\title{
In vitro and in situ study of postharvest apple blue mold biocontrol by Aureobasidium pullulans: Evidence for the involvement of competition for nutrients
}

\author{
Sanae Krimi Bencheqroun ${ }^{\text {a,c, },}$, Mohammed Bajji ${ }^{\mathrm{a}, 1}$, Sébastien Massart ${ }^{\mathrm{a}}$, \\ Mustapha Labhilili ${ }^{\text {b }}$, Samir El Jaafari ${ }^{\mathrm{c}}$, M. Haïssam Jijakli ${ }^{\mathrm{a}, *}$ \\ ${ }^{a}$ Unité de phytopathologie, Faculté Universitaire des Sciences Agronomiques, Passage des Déportés 2, 5030 Gembloux, Belgium \\ ${ }^{\mathrm{b}}$ Institut National de la Recherche Agronomique Guich, BP 415 Rabat, Morocco \\ ${ }^{\mathrm{c}}$ Université de Moulay Ismail, BP 4010 Meknès, Morocco \\ Received 11 January 2007; accepted 12 May 2007
}

\begin{abstract}
Aureobasidium pullulans strain Ach1-1 was selected for its effectiveness against blue mold caused by Penicillium expansum on stored apple fruit. The possible involvement of competition for nutrients in the biocontrol activity of this antagonistic strain was investigated both in vitro and in situ. For in vitro assays, the effect of strain Ach1-1 on germination percentages of $P$. expansum conidia was evaluated after a $24 \mathrm{~h}$ incubation period in the presence of increasing apple juice concentrations (0-5\%) using a system allowing the physical separation of both agents. In the absence of strain Ach1-1, conidial germination was strongly promoted by apple juice whatever the concentration. However, germination was significantly reduced by the presence of strain Ach1-1 except at the highest juice concentration. For conidia previously inhibited at $0.5 \%$ juice, germination after $24 \mathrm{~h}$ of incubation was partially recovered in the presence of strain Ach1-1 when fresh juice was added to a final concentration of 5\%, and completely restored at both 0.5 and $5 \%$ juice concentrations in the absence of strain Ach1-1. For in situ assays, strain Ach1-1 was very protective against $P$. expansum on postharvest wounded apples. However, the application of high concentrations of exogenous sugars, vitamins and most particularly amino acids, significantly reduced such protection. Time-course analysis of apple amino acids at the wound site revealed that these compounds were more depleted in wounds treated with strain Ach1-1 alone and especially in those treated with both agents (strain Ach1-1 and $P$. expansum) compared to wounds treated with P. expansum alone or to untreated ones. Exogenous amino acids, applied at high concentrations on apple wounds as a mixture of specific amino acid groups or as individuals, significantly decreased strain Ach1-1 efficacy against $P$. expansum. The present study provides in vitro and in situ evidence that competition for apple nutrients, most particularly amino acids, may be a main mechanism of the biocontrol activity of $A$. pullulans strain Ach1-1 against blue mold caused by $P$. expansum on harvested apple fruit.
\end{abstract}

(C) 2007 Elsevier B.V. All rights reserved.

Keywords: Amino acids; Aureobasidium pullulans; Biocontrol; Nutrient competition; Penicillium expansum; Postharvest apples

\section{Introduction}

Apple production is a complex process involving orchard, storage and marketing phases. Long-term storage of this important fruit has become possible due to modern postharvest technologies. However, postharvest diseases, especially those originating from wound infection at harvest or during postharvest handling and packing, can be a serious limiting factor for

\footnotetext{
* Corresponding author. Tel.: +32 81622437; fax: +32 81610126 .

E-mail address: jijakli.h@fsagx.ac.be (M.H. Jijakli).

1 These authors have equally contributed to this work.
}

such storage (Bondoux, 1992). Blue mold caused by Penicillium expansum Link is an important postharvest disease on apples worldwide and is an economic concern not only for the fresh fruit industry but also for the fruit processing industry because $P$. expansum is generally regarded as the major producer of the mycotoxin patulin (McKinley and Carlton, 1991). Until now, this disease has essentially been controlled by preand postharvest handling practices and the application of synthetic fungicides (Jijakli and Lepoivre, 2004). However, several reasons including development of fungicide-resistant pathogens, fungicide toxicity, and deregistration of some effective products, have motivated the search for alternative approaches. Biological control has emerged as one of the most promising disease 
management alternatives with different mechanisms of action compared to chemical fungicides (Punja and Utkhede, 2003; Spadaro and Gullino, 2004; Fravel, 2005; Massart and Jijakli, 2007). A number of yeasts and bacteria have been reported to control postharvest fruit decay effectively (Janisiewicz and Korsten, 2002). Despite progress in understanding their modes of action, only a few biocontrol products are currently registered for such control in Europe (Alabouvette et al., 2006), in comparison with other countries, especially the USA (e.g. Fravel, 2005). In this context, several strains of the yeast-like fungus Aureobasidium pullulans (de Bary) Arnaud, one of the most widespread and well adapted saprophytes (Blakeman and Fokkema, 1982), have been isolated and appear to be potential biocontrol agents based on their great effectiveness in controlling the main postharvest pathogens (e.g. Botrytis cinerea and $P$. expansum) on several important crops including apple, table grape and strawberry (Lima et al., 1999, 2003; Ippolito et al., 2000, 2005; Castoria et al., 2001; Adikaram et al., 2002).

Recently, a new potential strain named Ach1-1 was isolated from the surface of 'Golden Delicious' apples and selected for its strong antagonistic properties against both $P$. expansum and B. cinerea pathogens (Achbani et al., 2005), although the mechanism(s) underlying its biocontrol activity are still unknown. Nevertheless, a good understanding of such mechanisms is a prerequisite for identifying the main biocontrol features for a better screening of new potential biocontrol agents, to develop appropriate formulations allowing their expression, and to facilitate registration procedures. The present work was thus undertaken to investigate the possible involvement of competition for nutrients in the biocontrol activity of strain Ach1-1 against $P$. expansum. Although several possible mechanisms have been reported (Droby and Chalutz, 1994; Janisiewicz and Korsten, 2002; Massart and Jijakli, 2007), the main mode of action of yeast(-like) biocontrol agents is believed to be competition for nutrients and space (Droby and Chalutz, 1994; Lima et al., 1997; Janisiewicz et al., 2000; Castoria et al., 2001). According to the literature dealing with competition for nutrients and space using different antagonist/pathogen(/host) systems (Castoria et al., 1997, 2001; Lima et al., 1997; Janisiewicz et al., 2000; Guetsky et al., 2002; Vero et al., 2002): (i) most studies have considered either the in vitro or the in situ approach but not both, (ii) the contribution of the competition for nutrients and competition for space has rarely been considered separately, and (iii) in situ assays have been often performed using the Nutrient Yeast Dextrose Broth medium whose composition is not comparable with that of host tissues. In the present study, competition for nutrients as a mode of action of $A$. pullulans strain Ach1-1 against $P$. expansum was first examined in vitro using a system that allows discrimination between competition for nutrients and that for space (Janisiewicz et al., 2000) using increasing concentrations of apple juice. Then, the study was complemented by in situ biocontrol assays using high concentrations of major apple components (amino acids, vitamins and sugars) as well as by a time-course analysis of specific nutrients at the wound site in different contexts.

\section{Materials and methods}

\subsection{Microorganisms and fruit material}

The pathogen $P$. expansum strain 880 was isolated from infected apple fruit (INRA, Meknès, Morocco) and has been one of the most aggressive isolates in the collection (unpublished data). It was maintained on potato dextrose agar (PDA) at $4{ }^{\circ} \mathrm{C}$. A conidial suspension was obtained by flooding 10-dayold PDA cultures of $P$. expansum with sterile water containing $0.05 \%$ (v/v) Tween 20. Conidia concentration of the pathogen was determined with a hemacytometer.

The biocontrol agent used in this study was the yeast-like fungus A. pullulans (De Bary) Arnaud strain Ach1-1 isolated from the surface of healthy 'Golden Delicious' apples (Belgium). It was selected for its high antagonistic properties against P. expansum and B. cinerea (Achbani et al., 2005). Before each application, strain Ach1-1 was grown on PDA at $25^{\circ} \mathrm{C}$ for three subcultures of $24 \mathrm{~h}$. A cell suspension was obtained by flooding cultures with isotonic water $(0.85 \% \mathrm{NaCl})$. The cell concentration was determined and adjusted to obtain $10^{7}$ colony-forming units (CFU) $\mathrm{mL}^{-1}$ using a hemacytometer.

Apple fruits ('Golden Delicious') were bought from a local market and maintained for $1-2$ weeks in the dark at $1{ }^{\circ} \mathrm{C}$ until used. These fruits were produced by Limdor Bourdelas group (St.-Yrieix-La Perche, France). After harvest at their optimal maturity, they were stored in a controlled cold atmosphere until marketing without any chemical treatment. The same product was used in the present work for the period December 2005-April 2006.

\subsection{In vitro competition for nutrients}

For all in vitro tests, competition for nutrients was studied using the non-destructive method developed by Janisiewicz et al. (2000). Tissue culture plates with 24 wells (TC-test plates) and culture plate inserts provided with a diffusing membrane of $0.4 \mu \mathrm{m}$ pore size (Millicell-CM, Millipore, Belford, MA) attached to the bottom part of the cylinder were used. Such a system allows media nutrients and metabolite interchange with physical separation of the antagonist and the pathogen. Suspensions containing the biocontrol agent Ach1-1 (10 $\left.\mathrm{cfu} \mathrm{mL}^{-1}\right)$ in apple juice at various concentrations $(0,0.1,0.5,1$ and $5 \%)$ were dispensed into the wells of culture plates $(600 \mu \mathrm{L}$ per well). Cylinder inserts were placed in the wells and $P$. expansum suspensions $\left(2 \times 10^{5}\right.$ conidia $\left.\mathrm{mL}^{-1}\right)$ were dispensed inside the inserts $(400 \mu \mathrm{L}$ per cylinder). The plates were then incubated in the dark at $25^{\circ} \mathrm{C}$ for $24 \mathrm{~h}$. Controls were represented by cultures of $P$. expansum alone in the same apple juice concentrations as above. After incubation, inserts were removed from the wells and blotted from the bottom with a tissue paper. For each insert, the membrane was cut with a sharp scalpel, transferred to a glass slide, stained with lactophenolcotton blue and mounted for optical microscope observation. The effect of strain Ach1-1 on P. expansum on the different media was assessed by conidial germination percentage compared to the corresponding controls. Germinated conidia were counted 
within a sample of 100 conidia and using two membranes per treatment.

When an inhibitory effect on $P$. expansum conidia was observed during the first assay, a parallel set of culture plates with the inserts was prepared as above to evaluate the viability of the conidia and the possible suppression of the observed inhibition. Inhibited conidia in the antagonist suspension at $0.5 \%$ apple juice concentration were submitted to new nutritional conditions in the presence or absence of the antagonist. These new nutritional conditions were obtained in two ways. In one, an amount of apple juice was added to the same media of the first assay containing the antagonist to obtain concentrations of 0.5 or $5 \%$. In the other, inserts containing inhibited conidia were removed from culture plates and inserted into new ones containing apple juice at concentrations of $0,0.5$ or $5 \%$. After an additional $24 \mathrm{~h}$ of incubation in the dark at $25^{\circ} \mathrm{C}$, the percentage of germinated conidia was evaluated using two membranes per treatment and a total of 100 conidia per membrane.

\subsection{Biocontrol assays on apple wounds}

The efficacy of $A$. pullulans strain Ach1-1 against $P$. expansum was evaluated on apple wounds as previously described (Jijakli and Lepoivre, 1993) with some modifications. Fruits were wounded with a cork-borer (3 wounds of $4 \mathrm{~mm} \times 4 \mathrm{~mm} \times 2 \mathrm{~mm}$ per apple) and treated with $40 \mu \mathrm{L}$ of the antagonist suspension (or isotonic water for controls) at $10^{7} \mathrm{CFU} \mathrm{mL}^{-1}$. One hour later, the wounded sites were inoculated with $40 \mu \mathrm{L}$ of $P$. expansum preparation $\left(10^{5}\right.$ conidia $\left.\mathrm{mL}^{-1}\right)$. Apples were then incubated on wet filter paper in closed plastic boxes at $25^{\circ} \mathrm{C}$ in the dark for 5 days before measuring diameters of decay lesions. The percentage of lesion reduction was estimated according to the formula $\left(D_{\mathrm{c}}-D_{\mathrm{t}}\right) / D_{\mathrm{c}} \times 100$, where $D_{\mathrm{c}}$ and $D_{\mathrm{t}}$ are, respectively, the lesion diameters of the control and treated apples.

\subsection{In situ competition for nutrients}

To study a possible nutrient competition mechanism in situ, the effect of exogenous application of major apple components (amino acids, vitamins and sugars) on the biocontrol activity of strain Ach1-1 against P. expansum was evaluated on wounded apples. Biocontrol assays were performed as described above with an additional step consisting of the application of nutrient solutions in apple wounds. Three solutions were prepared by mixing most of the amino acids, vitamins and sugars known to be present in apple tissues to obtain concentrations higher than those reported for apple tissues (20,20 and 5 times, respectively) (Table 1) (USDA nutrient database for standard reference, release 14, 2001). One hour after inoculation of $P$. expansum, $40 \mu \mathrm{L}$ of either water (none) or one of the nutrient solutions were added per wound. Controls were treated with the same solutions in the absence of strain Ach1-1. Lesion diameters were measured after 5 days of incubation in the dark at $25^{\circ} \mathrm{C}$. The percentage of lesion reduction was evaluated as described above using 15 apples per treatment.
Table 1

Identity and concentration $\left(\mathrm{g} \mathrm{L}^{-1}\right)$ of amino acids, vitamins and sugars used for in situ competition for nutrients of $A$. pullulans (strain Ach1-1) against $P$. expansum on postharvest apples

\begin{tabular}{|c|c|c|}
\hline Nutrient group & Specific nutrient & $\begin{array}{l}\text { Concentration } \\
\left(\mathrm{g} \mathrm{L}^{-1}\right)^{\mathrm{a}}\end{array}$ \\
\hline \multicolumn{3}{|l|}{ Amino acids } \\
\hline \multirow[t]{3}{*}{ Group 1} & Serine & 1.9 \\
\hline & Glycine & 1.9 \\
\hline & Glutamic acid & 0.3 \\
\hline \multirow[t]{6}{*}{ Group 2} & Threonine & 1.7 \\
\hline & Arginine & 1.4 \\
\hline & Histidine & 0.7 \\
\hline & Alanine & 1.7 \\
\hline & Aspartic acid & 0.2 \\
\hline & Proline & 1.7 \\
\hline \multirow[t]{7}{*}{ Group 3} & Tryptophan & 0.5 \\
\hline & Leucine & 1.0 \\
\hline & Lysine & 2.9 \\
\hline & Methionine & 0.5 \\
\hline & Phenylalanine & 1.2 \\
\hline & Tyrosine & 0.01 \\
\hline & Valine & 2.1 \\
\hline \multirow[t]{7}{*}{ Vitamins } & Ascorbic acid & 1357.1 \\
\hline & Thiamin & 4.0 \\
\hline & Riboflavin & 3.3 \\
\hline & Niacin & 18.3 \\
\hline & Pantothenic acid & 145.2 \\
\hline & Pyrodixin & 11.4 \\
\hline & Tocopherol & 76.2 \\
\hline \multirow{3}{*}{ Sugars } & Sucrose & 88.6 \\
\hline & Glucose & 104.0 \\
\hline & Fructose & 252.5 \\
\hline
\end{tabular}

${ }^{\mathrm{a}}$ Concentrations of amino acids, vitamins and sugars correspond respectively to 20, 20 and 5 times those reported for apple tissues (USDA nutrient database for standard reference, release 14,2001 ).

\subsection{In situ competition for amino acids}

The effect of exogenous application of increasing concentrations of amino acids on the protective level of strain Ach1-1 against $P$. expansum was assessed using the same procedure as above. Amino acids known to be present in apple tissues were used at concentrations 2, 10 or 20 times the amount reported for apple tissues (Table 1) (USDA nutrient database for standard reference, release 14, 2001).

The effect of exogenous supply of amino acids on strain Ach1-1 growth was also evaluated. After $24 \mathrm{~h}$ of incubation, apple wound tissues were removed with a scalpel, placed in a sterile mortar with $5 \mathrm{~mL}$ of KPT buffer $(0.05 \mathrm{M}$ of potassium phosphate at $\mathrm{pH} 6.5$ and $0.005 \%$ Tween 80 ) and ground with a pestle. Five apples with three wounds each were used. For each apple, recovered cell suspensions from the three wounds were pooled, diluted $10^{3}$ and $10^{4}$ times, and plated on agar plates ( $50 \mu \mathrm{L}$ per plate) using one plate per dilution (i.e. 5 plates per dilution and per treatment). Plates were then incubated at $25^{\circ} \mathrm{C}$ for 2 days and the number of strain Ach1-1 colonies was recorded. 


\subsection{Assimilation of apple amino acids by the antagonist and/or the pathogen}

Wounded apples were distributed into four sets (10 apples/set): (1) non-treated apples (control), (2) apples treated with strain Ach1-1 alone (antagonist), (3) apples inoculated with $P$. expansum alone (pathogen), and (4) apples treated with strain Ach1-1 and then inoculated with P. expansum (antagonist + pathogen). The two microorganisms were used following the same concentrations and timing as for biocontrol assays. For each set, $50 \mu \mathrm{L}$ of KPT buffer were added to each wound and then recovered by pipeting $0,4,6,14$ and $24 \mathrm{~h}$ after the application of the antagonist. Samples of each set (30 samples) were pooled and their amino acid concentrations were determined by high-pressure liquid chromatography (HPLC) and detected by fluorescence. Samples were derivatized with 6-aminoquinolyl$\mathrm{N}$-hydroxysuccinimidyl carbamate (AccQ.Fluor) and separated on an amino acid column (Waters AccQ.Tag column) thermostatized at $37^{\circ} \mathrm{C}$. Amino acids were detected by a fluorescence detector (Waters 2475) with an excitation wavelength at $250 \mathrm{~nm}$ and an emission wavelength at $395 \mathrm{~nm}$. The identity of amino acids was confirmed by retention times using standards (Sigma Chemical Co.).

A parallel biocontrol assay was performed as previously described to evaluate the efficacy of strain Ach1-1 against $P$. expansum in the same conditions as for the test above.

\subsection{In situ competition for specific amino acids}

The effect of exogenous application of specific amino acids on the protective level of strain Ach1-1 against $P$. expansum was assessed as above. These amino acids were selected based on HPLC analysis (see Section 3) and were applied either as a mixture of amino acids or individually at a concentration 20 times that reported for apple tissues (Table 1).

\subsection{Statistical analysis}

For each experiment, a completely randomized design was used. Each experiment was repeated at least once with similar results. Data from one experiment were subjected to a two-way analysis of variance (ANOVA) using the Statistical Analysis System (SAS/STAT) software. The two independent factors were juice concentration and strain Ach1-1 (Figs. 1 and 2), 'nutrient' concentration and strain Ach1-1 (Figs. 3, 4, 7 and 8), and incubation time and treatment (Fig. 6). Data of Fig. 5 were subjected to a one-way analysis of variance with amino acid concentration as the independent factor. When significant differences were found, means were compared using the Tukey's HSD test at $P \leq 0.05$.

\section{Results}

\subsection{In vitro competition for nutrients}

Fig. 1 shows germination percentages of $P$. expansum conidia after $24 \mathrm{~h}$ of incubation at increasing apple juice concentrations

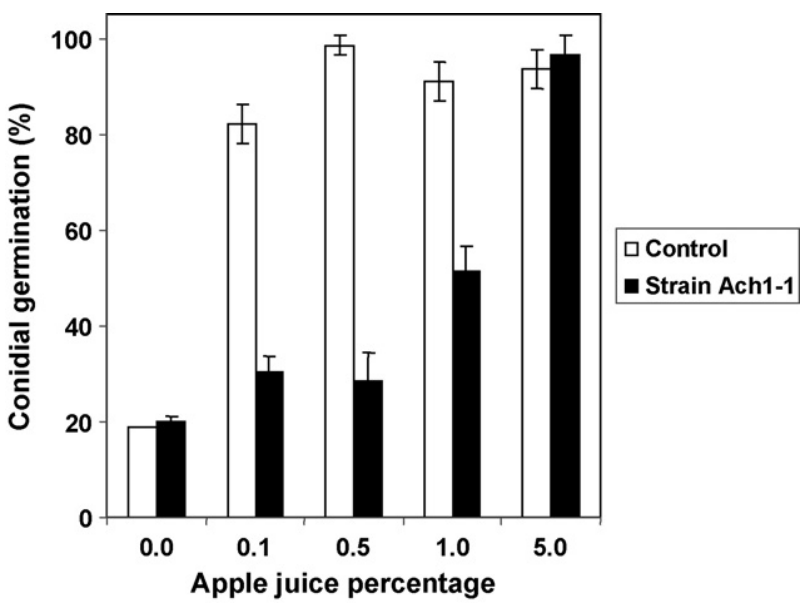

Fig. 1. Germination percentages of $P$. expansum conidia after $24 \mathrm{~h}$ of incubation without (control) or with A. pullulans (strain Ach1-1) as a function of apple juice concentration. Vertical bars represent S.E. $(n=2)$.

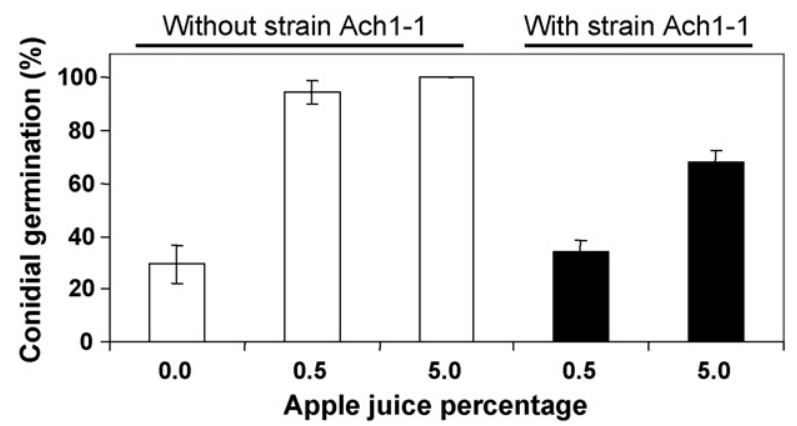

Fig. 2. Germination percentages of $P$. expansum conidia after $24 \mathrm{~h}$ of incubation without or with A. pullulans strain Ach1-1 as a function of apple juice concentration. These conidia were previously exposed to strain Ach1-1 in $0.5 \%$ apple juice for $24 \mathrm{~h}$. Vertical bars represent S.E. $(n=2)$.

without (control) or with the antagonist (strain Ach1-1). Analysis of variance showed a significant effect of juice concentration, presence of strain Ach1-1 and their interaction (data not shown). The lowest percentages were recorded at $0 \%$ juice concentration whatever the treatment (control or strain Ach1-1). In the absence of strain Ach1-1 (control), conidia of $P$. expansum ger-

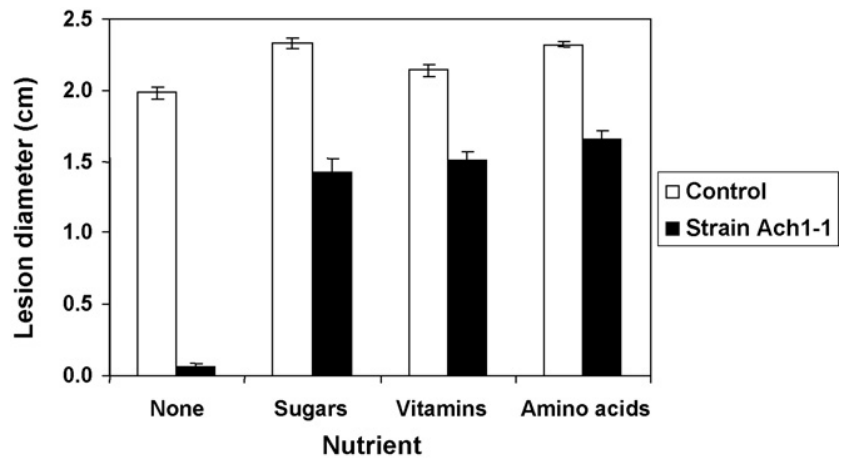

Fig. 3. Effect of exogenous application of sugars, vitamins or amino acids in apple wounds on lesion diameters $(\mathrm{cm})$ induced by $P$. expansum in the absence (control) or in the presence of A. pullulans (strain Ach1-1) after 5 days of incubation. Vertical bars represent S.E. $(n=45)$. 


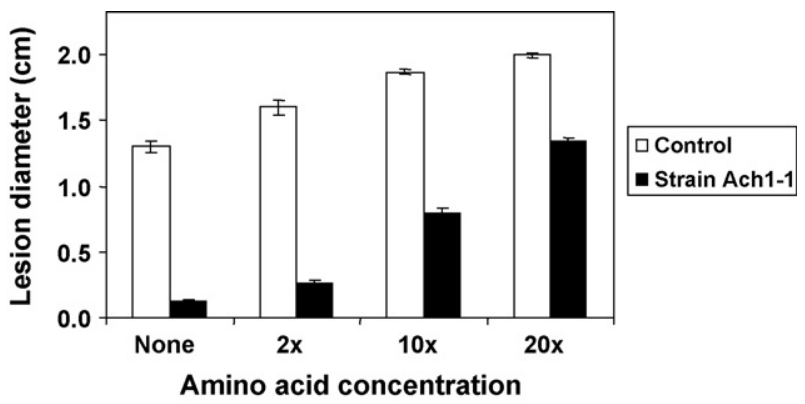

Fig. 4. Effect of exogenous amino acid application in apple wounds on lesion diameters $(\mathrm{cm})$ induced by $P$. expansum in the absence (control) or in the presence of A. pullulans (strain Ach1-1) after 5 days of incubation. Vertical bars represent S.E. $(n=45)$.

minated (82.5-98.5\%) within the first $24 \mathrm{~h}$ of incubation at all apple juice concentrations tested (Fig. 1). In the presence of strain Ach1-1, however, conidial germination was significantly reduced in apple juice except at the highest concentration. The highest inhibitory effect $(71 \%)$ of the biocontrol agent strain Ach1-1 was obtained at $0.5 \%$ juice concentration.

When cylinders containing inhibited conidia (after $24 \mathrm{~h}$ of incubation) at $0.5 \%$ juice with strain Ach1-1 were transferred to new wells containing increasing concentrations $(0,0.5$ or $5 \%)$ of fresh apple juice without strain Ach1-1, conidial germination after an additional incubation of $24 \mathrm{~h}$ was still inhibited in the absence of apple juice $(0 \%)$ but completely restored in the presence of both 0.5 and $5 \%$ apple juice concentrations (Fig. 2). However, the addition of fresh juice into wells containing inhibited conidia (after $24 \mathrm{~h}$ of incubation with the antagonist) to obtain concentrations of either 0.5 or $5 \%$ did not totally recover conidial germination $24 \mathrm{~h}$ later; germination percentages were 34.0 and $67.8 \%$, respectively (Fig. 2).

\subsection{In situ competition for nutrients}

In the absence of exogenous nutrients, strain Ach1-1 seemed very effective in reducing the lesion diameters provoked by $P$. expansum on wounded apples, the corresponding reduction per-

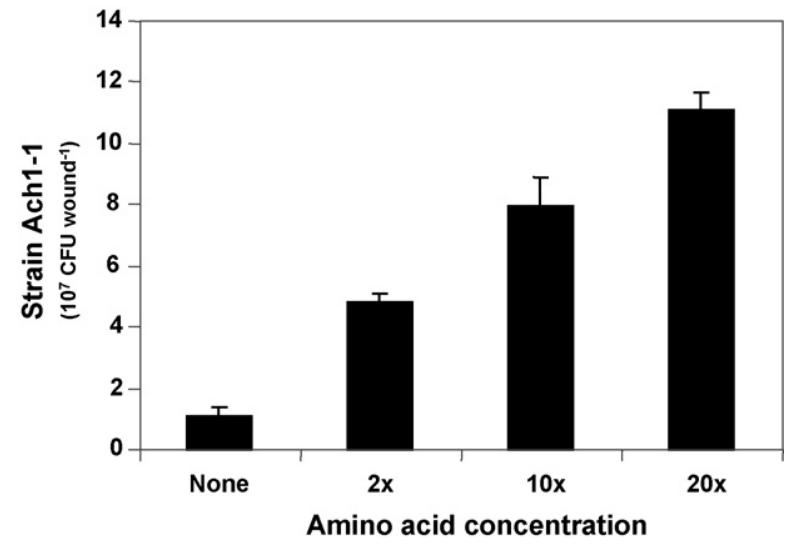

Fig. 5. Effect of exogenous amino acid application in apple wounds on population size $\left(10^{7} \mathrm{CFU}\right.$ wound $\left.{ }^{-1}\right)$ of A. pullulans strain Ach1-1 after $24 \mathrm{~h}$ of incubation. Vertical bars represent S.E. $(n=5)$. centage being $97.1 \%$ (Fig. 3). Analysis of variance showed a significant effect of the presence of strain Ach1-1 on the extent of infection (detailed data not presented). In controls, nutrient supply in apple wounds significantly enhanced the diameter of lesions. In the presence of strain Ach1-1, nutrient application strongly increased lesions caused by the pathogen (Fig. 3); percentages of lesion reduction afforded by strain Ach1-1 in response to sugars, vitamins and amino acids were 39.8, 29.4 and $28.4 \%$, respectively. Depending on the assays, the most important reduction of the antagonistic activity of strain Ach1-1 against $P$. expansum was obtained with amino acids (71-78\%) followed by vitamins (51-70\%) and finally by sugars (38-60\%) (detailed data not shown).

\subsection{In situ competition for amino acids}

In both controls and strain Ach1-1-treated wounds, lesion diameters developed by $P$. expansum significantly increased with increasing concentrations of amino acids supplied (Fig. 4). The application of strain Ach1-1 significantly reduced infection lesions whatever the amino acid concentration; the extent of the reduction decreased with increasing amino acid concentrations. The most important loss of strain Ach1-1 protection against $P$. expansum was obtained with the supply of the highest $(20 \times)$ amino acid concentration (Fig. 4).

Fig. 5 shows the effect of exogenous supply of amino acids on strain Ach1-1 growth in apple wounds after $24 \mathrm{~h}$ of incubation. Population size of the strain was significantly increased in response to the application of amino acids; the higher the amino acid concentration, the larger was the population size of the antagonist.

\subsection{Assimilation of apple amino acids by the antagonist and/or the pathogen}

HPLC analysis of the time-course pattern of (endogenous) amino acids in apple wounds indicates that the total amount of these compounds decreased during apple incubation, especially during the first $14 \mathrm{~h}$ following strain Ach1-1 application (Fig. 6). The most important reduction was observed in apple wounds treated with strain Ach1-1 and especially in those con-

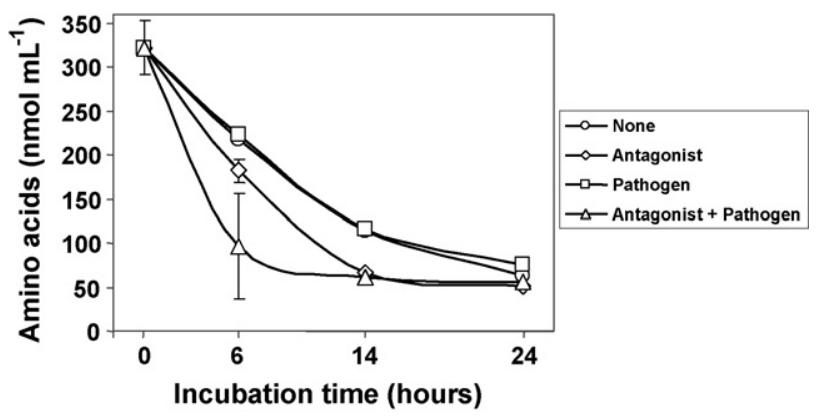

Fig. 6. Concentration (nmol mL $\mathrm{mL}^{-1}$ ) of total amino acids in apple wounds during the first $24 \mathrm{~h}$ of incubation. Wounds were either intact (none), treated with $A$. pullulans strain Ach1-1 alone (antagonist), inoculated with P. expansum alone (pathogen) or treated with strain Ach1-1 and then inoculated with $P$. expansum (antagonist + pathogen). Vertical bars represent S.E. $(n=2)$. 


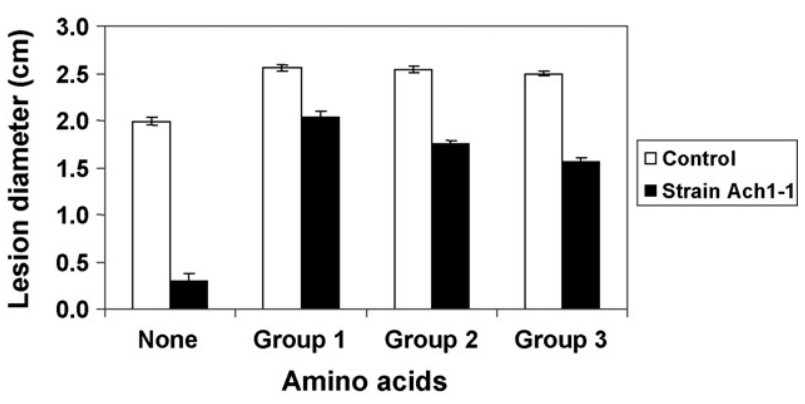

Fig. 7. Effect of exogenous application of different groups of specific amino acid in apple wounds on lesion diameters $(\mathrm{cm})$ induced by $P$. expansum in the absence (control) or in the presence of $A$. pullulans (strain Ach1-1) after 5 days of incubation. Vertical bars represent S.E. $(n=45)$.

taining strain Ach1-1 and $P$. expansum. The detailed analysis of HPLC data allowed us to classify the different amino acids analyzed into three groups based on their individual concentration and changes during incubation (Table 1). The first group includes serine, glycine and glutamic acid whose concentrations were largely reduced with incubation time. The second group contains amino acids (aspartic acid, histidine, arginine, threonine, alanine and proline) whose concentrations remained roughly unchanged during incubation. The remaining amino acids (tyrosine, valine, methionine, lysine, leucine, tryptophan and phenylalanine), which were present at very low concentrations, constitute the third group (detailed data not shown).

\subsection{In situ competition for specific amino acids}

Analysis of variance showed that lesion diameters developed by $P$. expansum were significantly affected by the amino acid group, by the presence of strain Ach1-1 and by their interaction (data not shown). In controls, lesion diameters developed by $P$. expansum were significantly higher in the presence than in the absence of exogenous amino acids independently of the group used (Fig. 7). In the presence of strain Ach1-1, amino acid supply significantly extended infection lesions; the most important effect was obtained with the first group (serine, glycine and glutamic acid). For these amino acids, the protection level was $20 \%$ only compared to $83.1 \%$ without any additional amino acids (Fig. 7).

Fig. 8 shows that the extent of lesions caused by $P$. expansum in the absence of strain Ach1-1 was not affected by individual application of serine or glycine but was reduced by the application of glutamic acid. Strain Ach1-1 significantly reduced the development of the pathogen regardless of the presence or absence of amino acids. The lowest level of protection was obtained with serine $(32.7 \%)$.

\section{Discussion}

A. pullulans strain Ach1-1 is a new potential biocontrol agent against postharvest apple blue mold. It was selected based on its high level of protection against $P$. expansum on wounded apples (Achbani et al., 2005). In the present work, the ability of this strain Ach1-1 to suppress P. expansum devel-

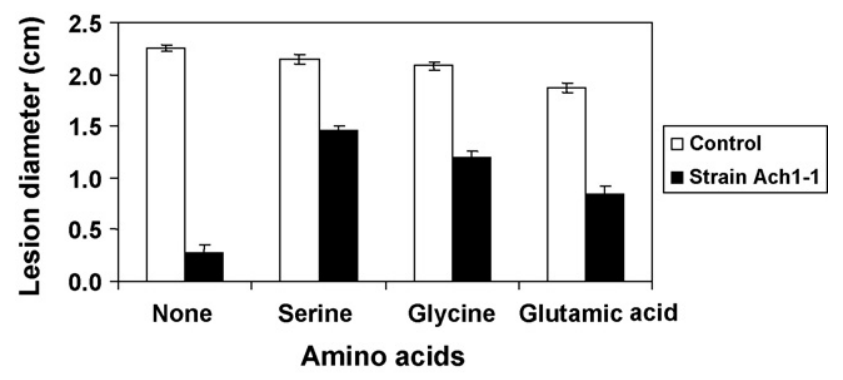

Fig. 8. Effect of exogenous application of serine, glycine or glutamic acid in apple wounds on lesion diameters $(\mathrm{cm})$ induced by $P$. expansum in the absence (control) or in the presence of A. pullulans (strain Ach1-1) after 5 days of incubation. Vertical bars represent S.E. $(n=45)$.

opment was repeatedly observed both in vitro and in situ. It prevented conidia germination in diluted apple juice concentrations (Fig. 1) and significantly reduced infection on wounded apples (Figs. 3, 4, 7 and 8) with a percentage of lesion reduction ranging from 83 to $97 \%$ depending on the assays. In order to maximize the potential use of strain Ach1-1 for the control of apple postharvest decay, an understanding of its mode(s) of action was necessary.

In the absence of strain Ach1-1, higher in vitro germination percentages of $P$. expansum conidia were recorded in the presence than in the absence of apple juice (Fig. 1), and the largest lesion diameters were obtained in apple wounds supplemented with exogenous nutrients (Figs. 3, 4 and 7). This confirms that $P$. expansum is nutrient-dependent and, as a necrotrophic pathogen, requires sufficient nutrients for its conidial germination and hyphal development. In the presence of strain Ach1-1, however, in vitro germination of the pathogen conidia was inhibited except at the highest apple juice concentration (Fig. 1) and the diameter of wound lesions was enhanced by supply of exogenous apple nutrients compared to non-treated wounds (Fig. 3). This suggests that strain Ach1-1 was effective against $P$. expansum in nutrient-limited environments only. Moreover, inhibited conidia were viable as they were still able to germinate when incubated at high apple juice concentrations without and even with the antagonist (Fig. 2). These data suggest therefore, that A. pullulans strain Ach1-1 out-competes $P$. expansum conidia for apple nutrients without affecting their viability. Its biocontrol activity was concentration-dependent (data not shown) and can be reversed either in vitro at high apple juice concentrations (Figs. 1 and 2) or in situ by the addition of exogenous apple nutrients (Figs. 3, 4, 7 and 8), which constitute supporting evidence for a possible involvement of competition for nutrients in the biocontrol activity of strain Ach1-1 against blue mold caused by $P$. expansum on stored apple fruit (Droby et al., 1989; Lima et al., 1997; Janisiewicz et al., 2000; Castoria et al., 2001; Meziane et al., 2006). If this is the case, strain Ach1-1 applied on apple surfaces will exert a fungistatic rather than fungicidal activity on $P$. expansum as it will deplete (limiting) nutrients available at the infection site (wounds) and inhibit conidia germination that depends on exogenous nutrients without affecting their viability. This will delay or prevent apple decay after harvest depending on the biocontrol agent concentration. In this way, competition for nutrients may be particularly effective as a sole mode of 
action or it may weaken the pathogen and predispose it to other mechanisms. In fact, other modes of action, including elicitation of host defence responses or production of lytic enzymes, might contribute simultaneously or sequentially with competition for nutrients to the biocontrol activity of strain Ach1-1 as was reported for other strains of the same species (Ippolito et al., 2000; Castoria et al., 2001).

It is important to mention that our in situ assays were conducted using high concentrations of amino acids, vitamins and sugars considering those reported for apple fruit tissues (USDA nutrient database for standard reference, release 14, 2001). Among these apple nutrients, amino acids seem to be more involved in competition between strain Ach1-1 and P. expansum than vitamins and more particularly than sugars, at least under our experimental conditions (Fig. 3). Moreover, an exogenous application of increasing concentrations of amino acids in apple wounds significantly lowered (by $64 \%$ at the highest concentration) the biocontrol activity of strain Ach1-1 against $P$. expansum (Fig. 4) without altering the development of these microorganisms (Figs. 4 and 5), suggesting that competition for apple amino acids by strain Ach1-1 plays an important role in suppressing $P$. expansum. This finding was strengthened by a time-course analysis of wound amino acids during apple incubation in which these nutrients were more depleted in the presence of strain Ach1-1 than in the presence of P. expansum and that the most rapid depletion was obtained in the presence of both agents (Fig. 6). This suggests that strain Ach1-1 assimilates apple amino acids better than $P$. expansum, most particularly serine, glycine and glutamic acid. Serine and glutamic acid were found to be two of three major amino acids in diluted apple juice and were completely depleted during the $24 \mathrm{~h}$ of incubation with another A. pullulans strain (ST1A24) in vitro (Janisiewicz et al., 2000). Therefore, these amino acids may be more involved than the other amino acids in the mechanism of competition. Indeed, their application on apple wounds at high concentrations either as a mixture (Fig. 7) or individually (Fig. 8) strongly lowered the biocontrol activity of strain Ach1-1, which indicates that these amino acids, and especially serine, appear to be the most limited nutrients in this competition.

Overall, our data provide strong evidence from both in vitro and in situ assays that competition for apple nutrients would be one of the main mechanisms underlying the biocontrol activity of A. pullulans strain Ach1-1 against P. expansum on stored apple fruits, amino acids being the most limited nutrients. Among these amino acids, glycine, glutamic acid and especially serine appear to be the most limited nutrients in this mechanism. The investigation will continue to find out the gene(s) involved in the uptake and the metabolism by the antagonist cells of these limited amino acids.

\section{Acknowledgements}

This work was financially supported by DGCD-CUD (Direction Générale de la Coopération au DéveloppementCommission Universitaire pour le Développement) as PIC (Projet Interuniversitaire Ciblé)-Morocco project. The authors are grateful to the Bio Technology Unit (Belgium) for their help for HPLC analysis.

\section{References}

Achbani, E.H., Mounir, R., El Jaafari, S., Douira, A., Benbouazza, A., Jijakli, M.H., 2005. Selection of antagonists of postharvest apple parasites: Penicillium expansum and Botrytis cinerea. Commun. Appl. Biol. Sci., Ghent Univ. 70, 143-149.

Adikaram, N.K.B., Joyce, D.C., Terry, L.A., 2002. Biocontrol activity and induced resistance as a possible mode of action for Aureobasidium pullulans against grey mould of strawberry fruit. Australas. Plant Pathol. 31, 223-229.

Alabouvette, C., Olivain, C., Steinberg, C., 2006. Biological control of plant diseases: the European situation. Eur. J. Plant Pathol. 114, 329-341.

Blakeman, J.P., Fokkema, N.J., 1982. Potential for biological control of plant diseases on the phylloplane. Annu. Rev. Phytopathol. 20, 167-192.

Bondoux, P. (Ed.), 1992. Maladies de conservation des fruits à pépins: pommes et poires. INRA, Paris.

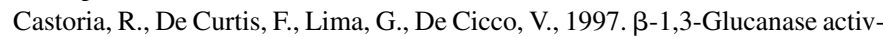
ity of two saprophytic yeasts and possible mode of action as biocontrol agents against postharvest diseases. Postharvest Biol. Technol. 12, 230 293.

Castoria, R., De Curtis, F., Lima, G., Caputo, L., Pacifio, S., De Cicco, V., 2001. Aureobasidium pullulans (LS-30) an antagonist of postharvest pathogens of fruits: study on its mode of action. Postharvest Biol. Technol. 22, 7-17.

Droby, S., Chalutz, E., 1994. Mode of action of biocontrol agents of postharvest diseases. In: Wilson, C.L., Wisniewski, M.E. (Eds.), Biological Control of Postharvest Diseases. Theory and Practice. CRC Press, Boca Raton, FL, pp. 365-389.

Droby, S., Chalutz, E., Wilson, C.L., Wisniewski, M.E., 1989. Characterization of the biocontrol activity of Debaryomyces hansenii in the biocontrol of Penicillium digitatum on grape-fruit. Can. J. Microbiol. 35, 794-800.

Fravel, D.R., 2005. Commercialization and implementation of biocontrol. Annu. Rev. Phytopathol. 43, 337-359.

Guetsky, R., Shtienberg, D., Elad, Y., Fischer, E., Dinoor, A., 2002. Improving biological control by combining biocontrol agents each with several mechanisms of disease suppression. Phytopathology 92, 976-985.

Ippolito, A., El Ghaouth, A., Wilson, C.L., Wisniewski, M., 2000. Control of postharvest decay of apple fruit by Aureobasidium pullulans and induction of defense responses. Postharvest Biol. Technol. 19, 265-272.

Ippolito, A., Schena, L., Pentimone, I., Nigro, F., 2005. Control of postharvest rots of sweet cherries by pre- and postharvest applications of Aureobasidium pullulans in combination with calcium chloride or sodium bicarbonate. Postharvest Biol. Technol. 36, 245-252.

Janisiewicz, W.J., Korsten, L., 2002. Biological control of postharvest diseases of fruits. Annu. Rev. Phytopathol. 40, 411-441.

Janisiewicz, W.J., Tworkoski, T.J., Sharer, C., 2000. Characterizing the mechanism of biological control of postharvest diseases on fruits with a simple method to study competition for nutrients. Phytopathology 90, 1196-1200.

Jijakli, M.H., Lepoivre, P., 1993. Biological control of postharvest Botrytis cinerea and Penicillium on apples. IOBC/WPRS Bull. 16, 106110.

Jijakli, M.H., Lepoivre, P., 2004. State of the art and challenges of post-harvest disease management in apples. In: Mukerji, K.G. (Ed.), Disease Management of Fruits and Vegetables. Fruit and Vegetable Diseases, vol. 1. Kluwer Academic Publishers, The Netherlands, pp. 59-94.

Lima, G., Ippolito, A., Nigro, F., Salerno, F., 1997. Effectiveness of Aureobasidium pullulans and Candida oleophila against postharvest strawberry rots. Postharvest Biol. Technol. 10, 169-178.

Lima, G., Arru, S., De Curtis, F., Arras, G., 1999. Influence of antagonist, host fruit and pathogen on the biological control of postharvest fungal diseases by yeasts. J. Ind. Microbiol. Biotechnol. 23, 223-229.

Lima, G., De Curtis, F., Castoria, R., De Cicco, V., 2003. Integrated control of apple postharvest pathogens and survival of biocontrol yeasts in semicommercial conditions. Eur. J. Plant Pathol. 109, 341-349. 
Massart, S., Jijakli, M.H., 2007. Use of molecular techniques to elucidate the mechanisms of action of fungal biocontrol agents: a review. J. Microbiol. Meth. 69, 229-241.

McKinley, E.R., Carlton, W.W., 1991. Patulin. In: Sharma, R.P., Salunkhe, D.K. (Eds.), Mycotoxins and Phytoalexins. CRC Press, Boca Raton, FL, pp. 191-236.

Meziane, H., Gavriel, S., Ismailov, Z., Chet, I., Chernin, L., Höfte, M., 2006. Control of green and blue mould on orange fruit by Serratia plymulthica strains IC14 and IC1270 and putative modes of action. Postharvest Biol. Technol. 39, 125-133.
Punja, Z., Utkhede, R., 2003. Using fungi and yeasts to manage vegetable crop diseases. Trends Biotechnol. 21, 400-407.

Spadaro, D., Gullino, M.L., 2004. State of the art and future prospects of the biological control of postharvest fruit diseases. Int. J. Food Microbiol. 91, 185-194.

Vero, S., Mondino, P., Burgueno, J., Soubes, M., Wisniewski, M., 2002. Characterization of biocontrol activity of two yeast strains from Uruguay against blue mold of apple. Postharvest Biol. Technol. 26, 91-98. 